\title{
Recovery from early cortical lesions in rats: 6. Cortical noradrenaline, cortical thickness, and development of spatial learning after frontal lesions or hemidecortications
}

\author{
BRYAN KOLB, JAMIE DAY, ROBBIN GIBB, and IAN Q. WHISHAW \\ University of Lethbridge, Lethbridge, Alberta, Canada
}

\begin{abstract}
Spatial learning, cortical thickness, cortical noradrenaline, and striatal dopamine were assessed in rats with bilateral or unilateral frontal cortex lesions or hemidecortications at 4 days of age. Training in a spatial learning task began at 25 days of age and was repeated at 60 and 150 days of age. The results showed that, relative to littermate controls, rats with bilateral frontal lesions were severely impaired at spatial learning, even when tested as young juveniles (around 25 days). The frontal lesions produced a 50\% decrease in noradrenaline in the remaining cortex and a thinning of the remaining cortex. However, although the cortical thickness and noradrenaline levels were correlated with one another, neither was correlated with behavior. Hemidecortication also produced a deficit in spatial learning in young and older animals alike, but, in contrast to the frontal lesions, hemidecortication led to an increase in noradrenaline in the remaining hemisphere and a small increase in cortical thickness. Neither of the latter measures was correlated with behavior. The results suggest that the neocortex is necessary for spatial navigation, even in young animals with an immature cortex. Furthermore, it appears that although neonatal lesions alter noradrenaline in the cortex, this noradrenergic alteration probably does not account for the severe behavioral effects of early lesions in rats.
\end{abstract}

We have shown in a series of experiments that neonatal damage to the neocortex of both rats and hamsters results in abnormal brain development and abnormal adult behavior, the precise effects varying with the developmental age at the time of the lesion and the locus of the lesion (e.g., Kolb, 1987; Kolb \& Whishaw, 1981, 1985a, $1985 \mathrm{~b})$. For example, bilateral damage to the frontal cortex in the first 5 days of life results in a brain that is grossly smaller than normal, has a small diencephalon, and has a remaining cortical mantle that is at least $20 \%$ thinner than in normal littermate controls (e.g., Kolb \& Whishaw, 1981). The changes in both brain size and cortical thickness can be observed as soon as $24 \mathrm{~h}$ after injury and are present for the rest of the animal's life (Kolb, 1987). These anatomical changes have significant consequences for the later behavior of the animals, as they develop behavioral deficits in adulthood that are much more severe than those observed after similar lesions in adulthood. It is unclear, however, how soon animals with early frontal lesions first show behavioral abnormalities. There are no obvious behavioral changes prior to weaning (about 21 days), and in our studies of behavioral development in hamsters, we have found that animals with neonatal frontal lesions showed normal food-hoarding and nest-building behavior

\footnotetext{
This research was supported by grants from the Natural Sciences and Engineering Research Council of Canada to B.K. and I.W. Reprint requests should be addressed to Bryan Kolb, Department of Psychology, University of Lethbridge, Lethbridge, Alberta T1K 3M4, Canada.
}

at the time of weaning but by 30 days of age the operated animals began to show deficits relative to littermate controls. Thus, animals appeared to "grow into" deficits, a phenomenon also reported in both monkeys and kittens with early lesions (Goldman, 1974; Kling, 1962; Villablanca, Olmstead, Levine, \& Marcus, 1978). Since we had previously found that species-typical and learned behaviors are differentially affected by frontal lesions in neonatal rats, we therefore wondered if deficits in learned tasks might appear later than the deficits in species-typical behavior that we observed in hamsters. And since we have shown repeatedly that there is a chronic and severe deficit in spatial learning in adult rats that have sustained frontal lesions in the first week of life (e.g., Kolb, 1987), we wondered how early this behavioral deficit might be observed. Since rats are capable of visual spatial navigation by about 22-25 days of age (Rudy, Stadler-Morris, $\&$ Albert, 1987), we decided to begin testing at 25 days of age with the goal of retesting the animals at 60 and 150 days of age.

Once the behavioral testing was completed, we availed ourselves of the opportunity to do catecholamine assays on the animals' brains. The primary reason for this was that it has been suggested that the severe anatomical and behavioral effects of early frontal lesions might be due, in part, to the interruption of noradrenergic projections that appear to invade the cortical plate very early in development (Kristt, 1979) and course through the frontal cortex en route to the posterior cortex (Morrison, Mol- 
liver, Grzanna, \& Coyle, 1981). The absence of noradrenaline (NA) may be especially important after early brain injury since it appears that, at least under some circumstances, the absence of NA is associated with decreased cortical plasticity. For example, depletion of NA from the rat neocortex shortly after birth completely abolishes the behavioral sparing that normally follows frontal cortical lesions performed around 7 days of age (Kolb \& Sutherland, 1986; Sutherland, Kolb, Becker, \& Whishaw, 1982). Similarly, NA depletion blocks corticospinal plasticity normally observed to follow neonatal motor cortex lesions in rats (Castro, Kartje-Tillotson, Barnes, \& Swenson, 1986). Thus, there is reason to suspect that NA may play a significant role in cortical plasticity following neonatal injury to the neocortex.

Rats with bilateral or unilateral lesions of the frontal cortex at 4 days of age, as well as rats with hemidecortications at the same age, were studied. The latter animals were included because we have found previously that, in contrast to the effects of small neonatal cortical lesions (which lead to the development of an abnormally thin cortex), hemidecortication can produce a thicker than normal cortex on the contralateral hemisphere (e.g., Kolb, Sutherland, \& Whishaw, 1983). These animals thus provided an interesting comparison group for both the behavioral and the biochemical studies.

\section{METHOD}

\section{Subjects}

The animals were 22 Long-Evans rats from three litters, which were divided into four groups: (1) 7 rats ( 5 female, 2 male) had their frontal cortex removed bilaterally on the 5th day of life (Day 5); (2) 5 rats ( 3 female, 2 male) had their frontal cortex removed unilaterally on Day 5 ; (3) 5 rats (3 female, 2 male) received hemidecortications on Day 5; and (4) 5 rats (3 female, 2 male) served as controls. Since there were no sex-related differences in behavioral or anatomical results, the data for the two sexes were combined for all analyses. The animals were maintained on a 12:12 h light:dark cycle and were tested during the light cycle.

\section{Surgery and Anatomy}

Cortical tissue was removed by aspiration (Kolb \& Whishaw, 1981). Anesthesia was by cooling. At the conclusion of the behavioral testing, the rats were decapitated, their brains were quickly removed and weighed, and samples of cortical tissue were taken from the sensorimotor cortex, visual cortex, and caudate-putamen of each hemisphere. Samples were taken by placing the brain on a cooled cutting block. The brain was cut coronally (with a razor blade) $5 \mathrm{~mm}$ from the frontal pole and $3 \mathrm{~mm}$ from the posterior pole. The frontal and rear pieces were dissected in ice-cold saline. The remaining brain was placed in a $10 \%$ Formalin solution until it sank and was then cut frozen at $40 \mu$. The sections between the cortical sample sites were saved, mounted on slides, and stained with cresyl violet. Cortical thickness measurements were made by taking three measurements from each hemisphere, one each from Areas P2, P1, and Oc2M of Zilles (1985).

\section{Biochemical Assays}

Biochemical assays were performed using high-performance liquid chromatography with electrochemical detection (Felice, Felice, \& Kissinger, 1978; Robinson, Becker, Young, Akil, \& Castaneda,
1987). Immediately after dissection, pieces of brain tissue were weighed and then homogenized in $400 \mu \mathrm{l} 0.05 \mathrm{~N} \mathrm{HClO}_{4}$ containing $100 \mathrm{ng} 3,4$ dihydroxybenzylamine hydrobromide as an internal standard and $0.8 \mathrm{mM} \mathrm{NaHSO} 4$ as a reducing agent. A standard curve [tissue blank plus five standards containing known amounts of NA (free base) and dopamine (DA) $\mathrm{HCl}$ ] was run with each assay. Samples were centrifuged at $12,000 \mathrm{~g}$ for $5 \mathrm{~min}$. After centrifugation, all of the supernatant was transferred to conical tubes containing $20 \mathrm{mg}$ acid-washed alumina and $200 \mu \mathrm{l} 3 \mathrm{M}$ Tris$\mathrm{HCl}\left(\mathrm{pH} 8.6\right.$ at $\left.4^{\circ} \mathrm{C}\right)$. Samples were immediately vortexed for $1 \mathrm{~min}$ and shaken on a reciprocal shaker for $10 \mathrm{~min}$. Alumina was washed twice with $600 \mu \mathrm{l} 6 \mathrm{mM}$ Tris- $\mathrm{HCl}\left(\mathrm{pH} 8.6\right.$ at $5^{\circ} \mathrm{C}$ ) and twice with $600 \mu \mathrm{l} \mathrm{H}{ }_{2} \mathrm{O}$. After completely removing the $\mathrm{H}_{2} \mathrm{O}$, the catecholamines were extracted with $200 \mu \mathrm{l}$ of $0.05 \mathrm{~N} \mathrm{HClO}_{4}$ by centrifugation for $2 \mathrm{~min}$. The supernatant was immediately assayed. The mobile phase was composed of 3 parts $0.1 \mathrm{M}$ citric acid, 2 parts $0.1 \mathrm{M} \mathrm{NaHPO}$, $0.0004 \%$ sodium octyl sulfate, and $15 \%$ methanol (pH 3.35). The mobile phase was pumped at $1 \mathrm{ml} / \mathrm{min}$ and continuously recycled. The detector potential was set at $0.72 \mathrm{~V}$ versus $\mathrm{Ag} / \mathrm{AgCl}$ reference electrode. Samples of $10 \mu \mathrm{l}$ were assayed with a sensitivity of $50 \mathrm{pg} / \mathrm{mg}$ for NA and $100 \mathrm{pg} / \mathrm{mg}$ for DA.

\section{Spatial Navigation}

Spatial navigation was assessed in a swimming pool (Morris, 1981) and was based upon a procedure devised by Sutherland, Whishaw, and Kolb (1983). Two different-sized pools were used. In the first test, the pool consisted of a circular tank $(85 \mathrm{~cm}$ diam; $45 \mathrm{~cm}$ high), the inside of which was painted white, and was filled to a height of $25 \mathrm{~cm}$ with approximately $18^{\circ} \mathrm{C}$ water in which $1,000 \mathrm{ml}$ of instant powdered skim milk was dissolved. A clear Plexiglas platform $(11 \times 12 \mathrm{~cm})$ was present inside the pool; its top surface was $14 \mathrm{~mm}$ below the surface of the water. In the second and third tests, the pool was $150 \mathrm{~cm}$ in diameter but all other measurements were the same.

A trial consisted of placing a rat by hand into the water, facing the wall of the pool, at one of four equally spaced starting locations around the pool's perimeter. Within each block of four trials, each rat started at the four starting locations but the sequence of locations was randomly selected. Rats were given eight trials per day, with an intertrial interval of approximately $5 \mathrm{~min}$. The latency to climb upon the platform was recorded for each trial.

Behavioral testing was conducted on Days 25, 26, and 27 of life and then again on Days 60-64 and on Days 150 and 151. The animals were swum in the small pool on the first 3 days and in the large pool (in a different room) thereafter. To determine if the animals could swim to a visible platform, a probe trial was used on Day 27 in which a visible platform, which was painted black and rose $18 \mathrm{~mm}$ above the water level, replaced the invisible platform.

\section{RESULTS}

The area of lesion in the brains could not be examined histologically since this region, including the caudateputamen, was dissected for catecholamine assay. Nonetheless, the frontal lesions appeared virtually identical to those we have described previously (e.g., Kolb, 1987; Kolb \& Whishaw, 1981). They included all of the dorsal anterior cingulate and prelimbic cortex medially, as well as most of the motor cortex at the same plane (see photographs and photomicrographs in Kolb \& Whishaw, 1981, or Kolb, Zaborowski, \& Whishaw, 1989). The hemidecortications removed all of the neocortex unilaterally and in no case was there damage to the contralateral 
hemisphere. These lesions also were similar to those we have described previously (e.g., Kolb et al., 1983).

\section{Cortical Thickness}

The cortical thickness measurements showed that frontal lesions decreased thickness relative to control thickness, as illustrated in Figure 1. The decrease was greatest in the bilateral frontal group and in the hemisphere ipsilateral
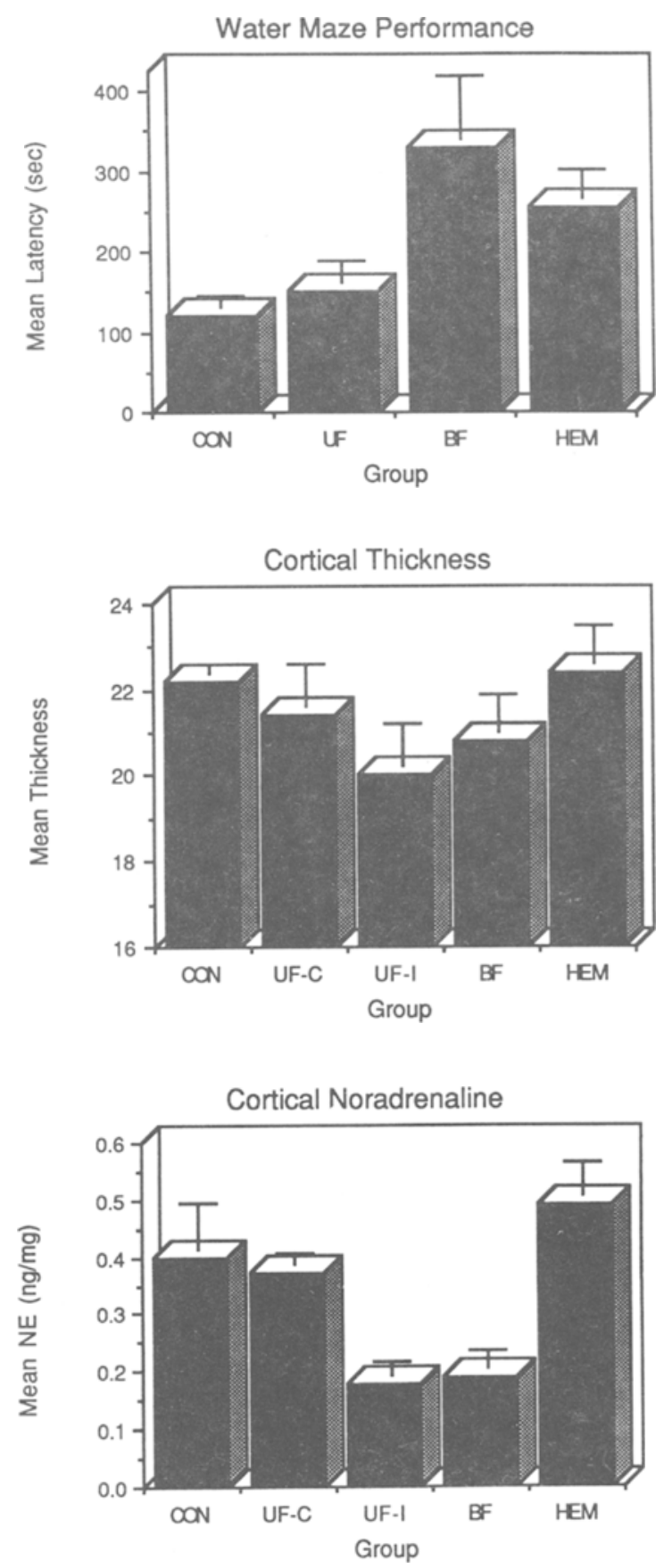

Figure 1. Summary of cortical thickness, water-maze performance, and cortical noradrenaline assays. to the lesion in the unilateral group, as we have reported previously (Kolb et al., 1989). An analysis of variance (ANOVA) on the thickness at the three points measured found a significant main effect of group $[F(3,17)=4.12$, $p=.023]$ and measurement $[F(2,34)=5.29, p<.01]$, but not the group $\times$ measure interaction $[F(6,34)=0.5$, $p=.83$ ]. Follow-up tests (Fisher's PLSD) found that the bilateral frontal group and the ipsilateral cortex of the unilateral frontal group were thinner than the cortex of the control and hemidecorticate groups $(p s<.05)$; no other differences reached significance.

\section{Noradrenaline Assay}

The frontal lesions were associated with large reductions in cortical NA in both the anterior and the posterior samples, as shown in Table 1, whereas the hemidecortications were associated with an increased level of NA in the remaining hemisphere. An ANOVA was performed by taking the mean NA content of the comparable samples in the two hemispheres of the control and bilateral frontal rats, but the operated and normal hemispheres of the unilateral frontal group were considered as separate groups. Sample location was treated as a repeated measure. The analysis showed a main effect of group $[F(4,22)$ $=5.54, p=.003]$, but neither the anterior/posterior difference nor the interaction were significant $[F(1,22)$ $=0.59, p=.47$, and $F(4,22)=1.0, p=.42$, respectively]. Follow-up tests (Fisher's PLSD) found the bilateral frontal group and the lesion side of the unilateral frontal group to have significantly lower NA than all other groups. One additional set of comparisons was significant, namely, the posterior NA measure in the hemidecorticates was greater than that in any of the other groups.

Analysis of the NA content of the caudate-putamen revealed no group differences $[F(4,22)=0.523, p=.72]$.

\section{Dopamine Assay}

The frontal lesions had no effect on DA, as an ANOVA showed no group effect $[F(5,31)=2.1, p=.0974$; see Table 1]. In contrast, however, the hemidecorticate rats had a higher DA content in the unoperated hemisphere $[t(9)=5.5, p<.001]$.

\section{Spatial Navigation}

The control rats learned the task very rapidly, even in the initial testing on Day 25 (Figure 2). After the first block of trials, they reliably swam to the platform, and on the fifth block, when the platform was visible, they swam directly to it. When retested 30 days later in a different room and in a larger tank, the control animals acquired the new version with substantial savings (see Figure 2). When the platform was moved, they took longer to find it since they persisted in swimming in the previously correct quadrant of the pool. When tested 3 months later (Day 150), the animals showed virtually complete savings. The rats with unilateral frontal lesions performed virtually identically to the control rats (Figure 2). In contrast, both the hemidecorticate and the bilateral frontal 
Table 1

Summary of Neurochemical Measures

\begin{tabular}{llccc}
\hline & \multicolumn{2}{c}{ Cortical NA } & & \\
\cline { 2 - 5 } \multicolumn{1}{c}{ Group } & Anterior & Posterior & Striatal NA & Striatal DA \\
\hline Control & $.441 \pm .08$ & $.361 \pm .08$ & $.108 \pm .01$ & $23.2 \pm 2.64$ \\
Bilateral Frontal & $.196 \pm .05^{*}$ & $.199 \pm .03^{*}$ & $.121 \pm .02$ & $22.5 \pm 1.72$ \\
Unilateral Frontal: Ipsilateral & $.195 \pm .04^{*}$ & $.155 \pm .03^{*}$ & $.140 \pm .03$ & $21.0 \pm 2.76$ \\
Unilateral Frontal: Control & $.332 \pm .09$ & $.351 \pm .06$ & $.096 \pm .03$ & $15.7 \pm 2.38$ \\
Hemidecordicate: Ipsilateral & & & $.167 \pm .05$ & $20.5 \pm 3.20$ \\
Hemidecordicate: Control & $.480 \pm .07$ & $.500 \pm .06^{*}$ & $.173 \pm .07$ & $31.0 \pm 6.40 \dagger$
\end{tabular}

Note-Values are expressed in $\mathrm{ng} / \mathrm{mg}$ wet weight. *Differs significantly from the other groups, $p<.05$ or bet-

ter. + Differs significantly from the other hemisphere, $p<.01$.

operates performed the test very poorly in the initial test, and even after four trial blocks they were taking five times as long as control animals to find the platform. When these groups were retested 30 days later, they showed little savings and were again very poor at the task and reached an asymptotic performance level that was about twice as long as the normal animals. Finally, when retested 3 months later, they displayed substantial improvement and performed nearly as well as the control animals.

An ANOVA on water-maze performance showed a significant main effect of group $[F(3,17)=3.3, p<.05]$ and practice $[F(19,323)=20.5, p<.001]$, and a significant group $\times$ practice interaction $[F(57,323)=1.5$, $p<.05]$. These effects are all evident in Figure 2. A follow-up comparison on overall group performance showed that the control and unilateral frontal groups differed significantly from the hemidecorticate and bilateral frontal groups $(p s<.05)$. Neither pair of groups differed among themselves $(p s>.10)$.

\section{Correlations}

Since one of the goals of the present research was to consider the possibility that reduced NA levels might lead to the development of a thinner cortex and/or poor spatial learning, we did a correlation matrix on water-task performance, posterior NA, posterior cortical thickness, and grouping. Table 2 shows that grouping correlated significantly ( $p<.05$ or better) with every variable, and that NA correlated significantly with cortical thickness but not with water-task performance. The failure to observe a correlation between NA and behavior is consistent with our previous observations that NA depletion alone has little effect on water-maze performance (e.g., Sutherland et al., 1982; Whishaw, Sutherland, Kolb, \& Becker, 1986).

\section{DISCUSSION}

The present experiments are part of a series of studies in which we have tried to identify some of the anatomical and behavioral consequences of early cortical injury in rodents (e.g., Kolb, 1987; Kolb et al., 1983; Kolb \& Whishaw, 1981, 1989; Whishaw \& Kolb, 1984, 1988). In our initial studies of rats with neonatal frontal ablations, we were struck by the nearly normal performance of animals on various learning tasks on which severe impairments follow similar removal in adulthood (e.g., Kolb \& Nonneman, 1978; Kolb \& Whishaw, 1981). However, in subsequent studies, we found that (1) sparing was less than complete or absent on some learning tasks, especially spatial place learning; (2) there was virtually no sparing on tests of species-typical behavior (e.g., Kolb \& Whishaw, 1981, 1985b); (3) deficits might appear on learning tests that are not normally affected by removal of the frontal cortex in adulthood (e.g., Kolb \& Holmes, 1983); and (4) the precise locus of lesion and age at surgery predict the extent of behavioral sparing (Kolb, 1987; Kolb \& Tomie, 1988; Kolb \& Whishaw, 1985a). Furthermore, we found that behavioral deficits were not immediately apparent, as animals appeared to "grow into" their deficits (Kolb \& Whishaw, 1985b), a result shown by others as well in studies of rats (Hicks \& D'Amato, 1970), kittens (Villablanca et al., 1978), and monkeys (Goldman, 1974) with neonatal cortical lesions. The results of the current experiments show that not all behavioral deficits appear gradually, however, as rats with neonatal frontal lesions are severely impaired at spatial navigation in the Morris water task at 25 days of age, which is about the time that normal animals can first solve this task (Rudy et al., 1987). This result was unexpected, but so, too, was our finding that even though the animals performed poorly on the early testing, they appeared to benefit from it, as they were able to acquire the task later in adulthood. We have previously found that even extensive training in adulthood (i.e., 20 days of training) did not allow animals with similar lesions to perform as well. This suggests that the early experiences of animals with neonatal cortical injuries may significantly influence later behavioral performance. This result is consistent with findings that raising animals in "enriched" environments attentuates the effects of early frontal lesions (e.g., Kolb \& Elliott, 1987; Whishaw, Zaborowski, \& Kolb, 1984; Will, Rosenzweig, \& Bennett, 1976).

\section{Noradrenaline and Behavior}

It has been proposed that one difficulty with making conclusions from frontal cortex lesions in rats is that the lesions disrupt noradrenergic fibers en passant to the posterior cortex (Morrison et al., 1981). Thus, the effects of frontal lesions may result, in part, from a disruption 
A

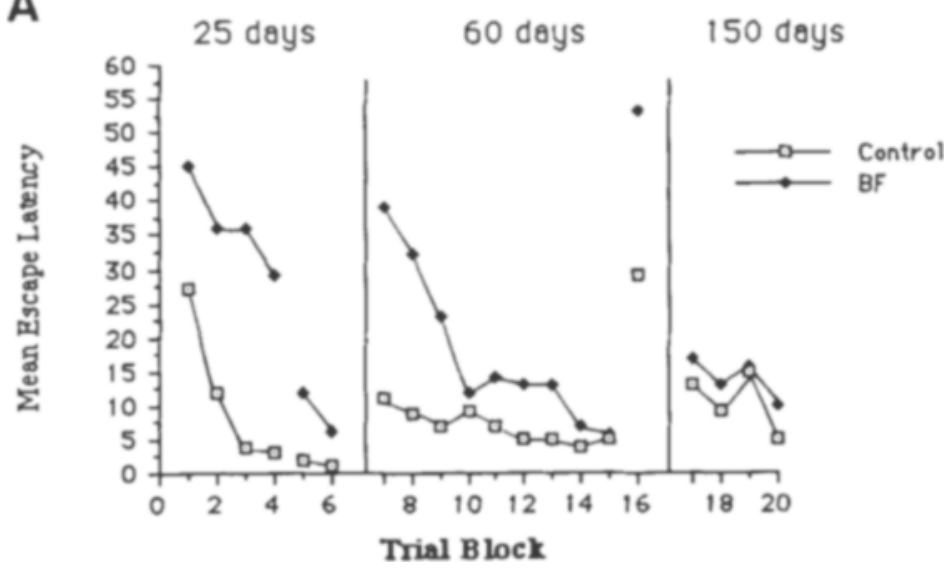

B
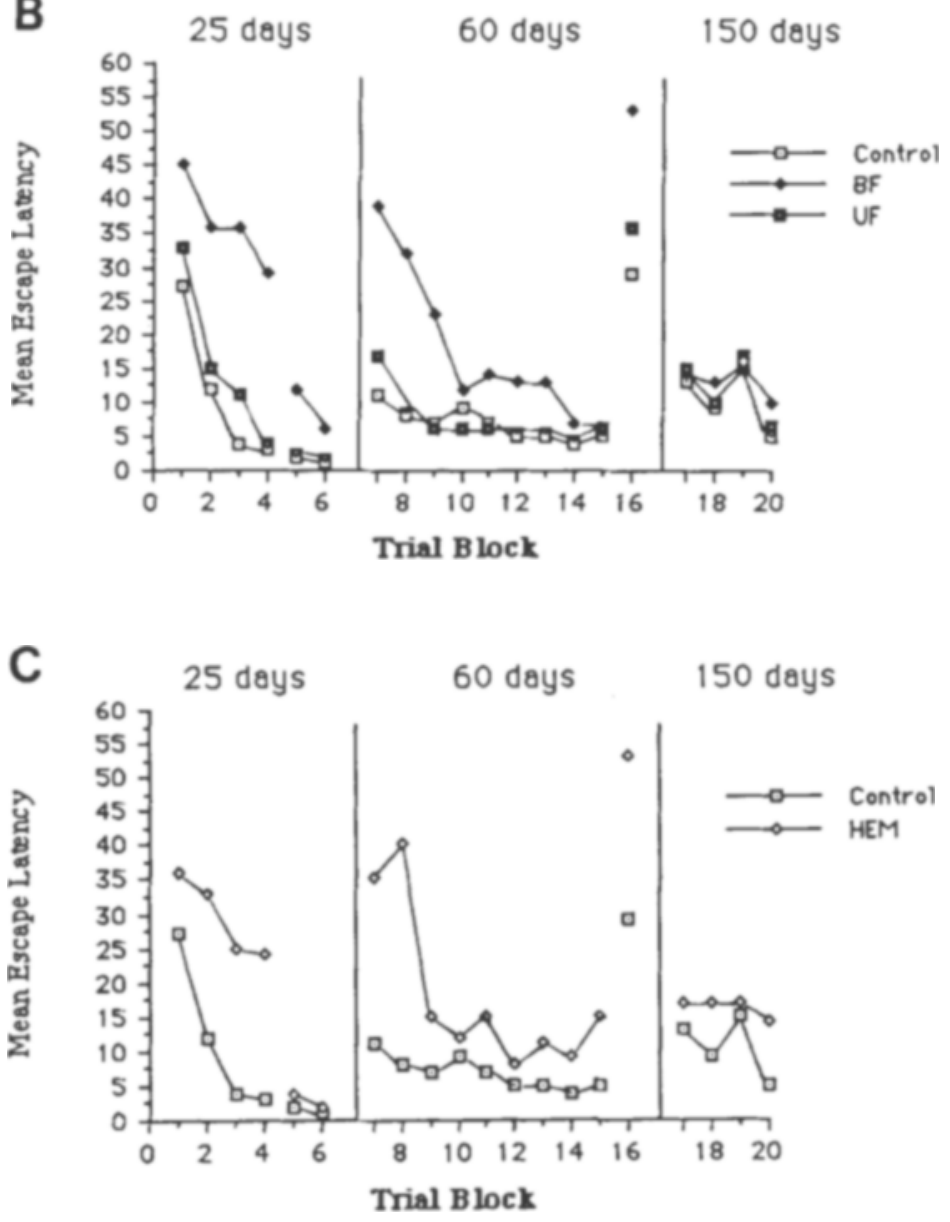

Figure 2. Summary of water-maze performance. Rats were first tested at 25 days of age, then again at 60 and 150 days. Trial Blocks 5 and 6 were to a black, visible platform. Trial Block 16 was a probe trial in which the platform was moved $180^{\circ}$. Both hemidecorticate and bilateral frontal rats showed a large impairment when tested at 25 and 60 days of age but good retention at 150 days of age. Unilateral frontal lesions had little effect on behavior. 
Table 2

Correlation Matrix for Frontal and Control Rats

\begin{tabular}{lcccc}
\hline & Maze & NA & Cortex & Group \\
\hline Water Maze & 1 & & & \\
Posterior NA & .135 & 1 & & \\
Cortex & .237 & $.428^{*}$ & 1 & 1 \\
Group & $.514^{*}$ & $.517^{*}$ & $.615^{*}$ & 1 \\
\hline
\end{tabular}

${ }^{*} p \mathrm{~s}<.05$ or better.

of posterior neocortical function. We found no correlation between NA and behavior in the present study, and in previous studies we have not been able to identify any behavioral correlates of complete NA depletion in the neocortex after neonatal injections of 6-hydroxydopamine (Sutherland et al., 1982; Whishaw et al., 1986). Thus, it seems difficult to relate the severe behavioral disruptions following early frontal lesions directly to NA depletion of the remaining cortex. One difficulty remains, however. Although the level of NA in the cortex in adulthood may be unrelated to behavior, the level of NA in the cortex during infancy may be a critical factor in development, and we did not measure it in the current study.

The increase in cortical NA and striatal DA in the intact hemisphere of hemidecorticate rats is intriguing since there is consistent behavioral sparing after neonatal hemidecortication, especially on tests of motor skills (e.g., Hicks \& D'Amato, 1970; Kolb \& Tomie, 1988).

\section{Noradrenaline and Cortical Development}

There was a significant correlation between cortical thickness and NA levels in the cortex adjacent to the thickness measurement. This result implies that the presence of NA may influence neuropil development, a conclusion that has been reached previously by others (e.g., Onteniente et al., 1980; Parnavelas \& Blue, 1982) but that has been controversial (e.g., Lidov \& Molliver, 1982). In a related study, Kolb and Sutherland (1986) measured cortical thickness after neonatal 6-hydroxydopamine lesions and frontal lesions at 4,7 , or 10 days of age, and found that, in every case, the cortex was thinner after the combined lesion than after the cortical lesion alone. Furthermore, NA lesions alone had no effect on cortical thickness. Thus, it may be that the role of NA in neuropil development is especially important after brain injury or other environmental events (e.g., Brenner, Mirmiran, Uylings, \& van der Gugten, 1985; Mohammed, Jonsson, \& Archer, 196; Pappas et al., 1987).

\section{REFERENCES}

Brenner, E., Mirmiran, M., Uylings, H. B. M., \& van der GugTEN, J. (1985). Growth and plasticity of rat cerebral cortex after central noradrenaline depletion. Experimental Neurology, 89, 264-268.

Castro, A. J., Kartje-Tillotson, G., Barnes, D., \& Swenson, R. S. (1986). Disruption of corticospinal plasticity by 6-hydroxydopamine as measured by intracortical microstimulation in rats. Developmental Brain Research, 24, 295-298.

Felice, L. J., Feuice J. D., \& Kissinger, P. T. (1978). Determination of catecholamines in rat brain parts by reverse phase ion-paired liquid chromatography. Journal of Neurochemistry, 31, 1461-1465.
Goldman, P. S. (1974). An alternative to developmental plasticity: Heterology of CNS structures in infants and adults. In D. G. Stein, J. J. Rosen, \& N. Butters (Eds.), Plasticity and recovery of function in the central nerwous system (pp. 149-174). New York: Academic Press.

Hicks, S. P., D'Amato, C. J. (1970). Motor-sensory and visual behavior after hemispherectomy in newborn and mature rats. Experimental Neurology, 29, 416-438.

KLING, A. (1962). Amygdalectomy in the kitten. Science, 137, 429. KolB, B. (1987). Recovery from early cortical damage in rats: 1. Differential behavioural and anatomical effects of frontal lesions at different ages of neural maturation. Behavioural Brain Research, 25, 205-220.

KoLB, B., ELLOTT, W. (1987). Recovery from early cortical damage in rats: 2. Effects of experience on anatomy and behavior following frontal lesions at 1 or 5 days of age. Behavioural Brain Research, 26, 47-56.

KolB, B., Holmes, C. (1983). Neonatal motor cortex lesions in the rat: Absence of sparing of motor behaviors and impaired spatial learning concurrent with abnormal cerebral morphogenesis. Behavioral Neuroscience, 97, 697-709.

Kolb, B. , Nonneman, A. J. (1978). Sparing of function in rats with early prefrontal cortex lesions. Brain Research, 151, 135-148.

KolB, B., SUTHERLAND, R. J. (1986). A critical period for noradrenergic modulation of sparing from neocortical parietal cortex damage in the rat. Society for Neuroscience Abstracts, 12, 322.

Kolb, B., Sutherland, R. J., \& Whishaw, I. Q. (1983). Abnormalities in cortical and subcortical morphology after neonatal cortical lesions in rats. Experimental Neurology, 79, 223-244.

KolB, B., \& TомIE, J. (1988). Recovery from early cortical damage in rats: 4 . Effects of hemidecortication at 1,5 , or 10 days of age on cerebral anatomy and behavior. Behavioural Brain Research, 28, 259-274.

Kolb, B., \& Whishaw, I. Q. (1981). Neonatal frontal lesions in the rat: Sparing of learned but not species-typical behavior in the presence of reduced brain weight and cortical thickness. Journal of Comparative \& Physiological Psychology, 95, 836-879.

KolB, B. \& WhISHAW, I. Q. (1985a). Earlier is not always better: Behavioral dysfunction and abnormal cerebral morphogenesis following neonatal cortical lesions in the rat. Behavioural Brain Research, 17, 25-43.

KolB, B., \& WishaW, I. Q. (1985b). Neonatal frontal lesions in hamsters impair species-typical behaviors and reduce brain weight and neocortical thickness. Behavioral Neuroscience, 99, 691-706.

Kolb, B., WhishaW, I. Q. (1989). Plasticity in the neocortex: Mechanisms underlying recovery from early brain damage. Progress in Neurobiology, 32, 235-276.

Kolb, B., Zaborowski, J., \& WhishaW, I. Q. (1989). Recovery from early cortical damage in rats: 5 . Unilateral lesions have different behavioral and anatomical effects than bilateral lesions. Psychobiology, 17, 363-369.

KRISTT, D. A. (1979). Development of neocortical circuitry: Quantitative ultrastructural analysis of putative monoaminergic synapses. Brain Research, 178, 69-88.

LiDov, H. G. W., Moluver, M. E. (1982). The structure of cerebral cortex in the rat following prenatal administration of 6hydroxydopamine. Developmental Brain Research, 3, 81-108.

Mohammed, A. K., Jonsson, G., \& ARCher, T. (1986). Selective lesioning of forebrain noradrenaline neurons at birth abolishes the improved maze performance induced by rearing in a complex environment. Brain Research, 398, 6-10.

MorRIS, R. G. M. (1981). Spatial localization does not require the presence of local cues. Learning \& Motivation, 12, 239-260.

Morrison, J. H., Molliver, M. E., Grzanna, R., \& Coyle, J. T. (1981). The intracortical trajectory of the coenuleo-cortical projections in the rat: A tangentially organized cortical afferent. Neuroscience, 6, 139-158.

Onteniente, B., Konig, N., Sievers, J., Jenner, S., Klemm, H. P., \& MARTY, R. (1980). Structure and biochemical changes in rat cerebral cortex after neonatal 6-hydroxydopamine administration. Anatomy \& Embryology, 159, 245-255.

Pappas, B. A., SaAri, M., Smythe, J., Murtha, S., Stange, K., 
\& INGS, R. (1987). Forebrain norepinephrine and neurobehavioral plasticity: Neonatal 6-hydroxydopamine eliminates enrichedimpoverished experience effects on maze performance. Pharmacology, Biochemistry \& Behavior, 27, 153-158.

Parnavelas, J. G., Blue, M. E. (1982). The role of the noradrenergic system on the formation of synapses in the visual cortex of the rat. Developmental Brain Research, 3, 140-144.

Robinson, T. E., Becker, J. B., Young, E. A., AKIL, H., \& Castaneda, E. (1987). The effects of footshock stress on regional brain dopamine metabolism and pituitary $\beta$-endorphin release in rats previously sensitized to amphetamine. Neuropharmacology, 26, 679-691.

Rudy, J. W., Stadler-Morris, S., \& Albert, P. (1987). Ontogeny of spatial navigation behaviors in the rat: Dissociation of "proximal" and "distal" cue-based behaviors. Behavioral Neuroscience, 101, 62-73.

Sutherland R. J., Kolb, B., Becker, J. B., \& Whishaw, I. Q. (1982). Cortical noradrenaline depletion eliminates sparing of spatial learning after neonatal frontal cortex damage in the rat. Neuroscience Letters, 32, 125-130.

Sutherland, R. J., Whishaw, I. Q., \& Kolb, B. (1983). A behavioural analysis of spatial localization following electrolytic, kainate- or colchicine-induced damage to the hippocampal formation in the rat. Behavioural Brain Research, 7, 133-153.

Villablanca, J. R., Olmstead, C. E., Levine, M. S., \& Marcus, R. J. (1978). Effects of caudate nuclei or frontal cortex ablations in kittens: Neurology and gross behavior. Experimental Neurology, 61, 615-634.
WhISHAW, I. Q., \& KoLB, B. (1984). Behavioral and anatomical studies of rats with complete or partial decortication in infancy: Functional sparing, crowding or loss, and cerebral growth or shrinkage. In R. Amli \& S. Finger. (Eds.), Recovery of function (pp. 117-138). New York: Academic Press.

WHISHAW, I. Q., \& KoLB, B. (1988). Sparing of skilled forelimb reaching and corticospinal projections after neonatal motor cortex removal or hemidecortication in the rat: Support for the Kennard doctrine. Brain Research, 451, 97-114.

Whishaw, I. Q., Sutherland, R. J., Kolb, B., \& Becker, J. B. (1986). Effects of neonatal forebrain noradrenaline depletion on recovery from brain damage: Performance on a spatial navigation task as a function of age of surgery and postsurgical housing. Behavioral \& Neural Biology, 46, 285-307.

Whishaw, I. Q., ZABorowsKI, J., \& KolB, B. (1984). Postsurgical enrichment aids adult hemidecorticate rats on a spatial navigation task. Behavioral \& Neural Biology, 42, 183-190.

WilL, B. J. E., Rosenzweig, J. R., \& BenNetT, E. L. (1976). Effects of differential environments on recovery from neonatal brain lesions, measured by problem-solving scores. Physiology \& Behavior, 16, 603-611.

ZiLLES, K. (1985). The cortex of the rat. Berlin: Springer-Verlag.

(Manuscript received July 19, 1988; revision accepted for publication May 5, 1989.) 